\title{
The congenital clubfoot - immunohistological analysis of the extracellular matrix
}

\author{
Arno Kerling' \\ Gisela \\ Stoltenburg-Didinger ${ }^{2}$ \\ Lena Grams' \\ Uwe Tegtbur' \\ Hauke Horstmann' \\ Momme Kück' \\ Holger Mellerowicz ${ }^{3}$ \\ 'Institute of Sports Medicine, \\ Hannover Medical School, \\ Hannover, Germany; ${ }^{2}$ Gisela \\ Stoltenburg-Didinger, Institute of \\ Cell and Neurobiology, Charité \\ Universitätsmedizin Berlin CCO, \\ Berlin, Germany; ${ }^{3}$ Holger Mellerowicz, \\ Clinic for Pediatric Orthopedics and \\ Traumatology, Helios Klinikum Emil \\ von Behring, Berlin, Germany
}

This article was published in the following Dove Press journal:

Orthopedic Research and Reviews

\begin{abstract}
Purpose: Congenital clubfoot is one of the most common limb disorders in humans and its etiology is still unclear. In order to better understand the pathogenesis of patients with primary clubfoot, we examined whether there are quantitative changes in the extracellular matrix (ECM; based on common interstitial collagens [C] like CI and CIII, microfilamentous collagens like CVI, noncollagenous proteins like undulin, and enzymes like matrixmetalloproteinase [MMP]-2 and tissue inhibitor of matrixmetalloproteinase [TIMP]-2 that are known to play a role in fibrogenesis and fibrolysis) of muscles involved in the foot deformity of patients with primary clubfoot corresponding to fibrosis.
\end{abstract}

Patients and methods: Thirty patients (age ranging from 4 months to 5 years and 7 months) with primary clubfoot were examined ( 23 male and 7 female patients), among whom 18 patients were affected on one side and 12 affected on both sides. Twenty-five biopsies were taken during the first operative foot correction (Crawford-McKay) and 5 in the context of relapses. Muscle biopsies were taken from the muscles involved in the defect (Musculus [M.] gastrocnemius and M. tibialis anterior) and from the M. vastus lateralis of the M. quadriceps femoris, which were treated as healthy comparison muscles. Quantitative analysis of the components of the ECM was performed using a computer-assisted fibrosis measurement of the immunohistochemically processed tissue samples.

Results: We found higher values for M. gastrocnemius for CI, CIII, CVI and undulin in comparison with M. vastus lateralis. However, values for TIMP-2 were reduced. We found no significant differences for the components of M. tibialis anterior and M. vastus lateralis. There were no quantitative differences between male and female or between patients affected on one side and both sides. In patients who underwent relapse surgery, CI, CIII, CVI, and undulin of the gastrocnemius were significantly higher, while TIMP-2 was significantly lower.

Conclusion: In the present study, we found manifest fibrosis in gastrocnemius due to quantitative changes in the ECM. In contrast to other studies, we found increasing fibrosis not just in contracted tissues but also in the muscle itself. Further studies are needed to clarify whether these changes are primarily responsible for the malfunction or whether they occur secondarily in the consequence of the dysfunction.

Keywords: pes equinovarus, clubfoot, extracellular matrix, fibrosis, collagens, TIMP-2

\section{Introduction}

Congenital clubfoot is one of the most common limb disorders in humans with a prevalence of $1-2 / 1000$ live births among Caucasians. ${ }^{1}$ The deformity appears with an adductus of the forefoot, a cavus of the midfoot, and an equinovarus of the hindfoot, for which there is a wide variation in clinical severity. ${ }^{2}$ There are many theories
Institute of Sports Medicine, Hannover Medical School, Carl-Neuberg-Straße I, 30625 Hannover, Germany

Tel +495II 5325499

Email kerling.arno@mh-hannover.de 
concerning the pathogenesis, and a multifactorial etiology including genetic, anatomic, vascular, and environmental factors (like smoking during pregnancy) is likely. ${ }^{2-5}$

In skeletal muscle, single muscle fibers are surrounded by endomysium that includes arterial and venous vessels as well as nerve twigs; the endomysium is connected with the perimysium that groups muscle fibers into bundles and fascicles. The extracellular matrix (ECM) consists of numerous proteins like collagens, glycoproteins, and proteoglycans, but not fats and nucleic acids. ${ }^{6}$ ECM can be divided into two main types: 1) the interstitial matrix - this surrounds the cells and is mainly composed of collagen (C) $\mathrm{CI}$ and fibronectin that form a tissue framework and 2) the basement membrane - this consists of CIV, fibronectin, and other proteins that separate the epithelium from the stroma and are responsible for cell organization. ${ }^{7}$ By creating specific environmental conditions, ECM significantly contributes to physiological and pathological reconstruction processes. Molecules that are functionally associated with the ECM (growth factors, matrix metalloproteinases [MMPs], tissue inhibitors of matrix metalloproteinases [TIMPs], receptors of the matrix like integrins and transmembrane proteoglycans) also belong to its components. ${ }^{8}$

Myofibroblasts are the main producers of ECM and are stimulated by transforming growth factor beta (TGF- $\beta$ ), interleukin-13, and other factors. Excess stimulation caused by chronic inflammation or tissue injury results in pathological fibrosis in which the excess ECM results in a positive feedback loop. ${ }^{7}$

Collagens are indispensable during the early stages of myogenesis, because only in the presence of an exogenous ECM, cultured myoblasts can form myotubes and express muscle-specific gene products such as acetylcholine receptors. ${ }^{9}$

During the synthesis of mature muscle fibers, the muscle cells increase at the expense of the ECM, until their occurrence in the mature muscle is limited to the endomysium around the myocytes and the larger peri- and endomysial bundles. A reduced function of CI, CIII, CIV, and CVI with decreasing growth activity of muscle cells in bovine Musculus (M.) semitendinosus is described by Nishimura et al. ${ }^{10}$

$\mathrm{CI}$ is the most common human protein in the ECM and can be found in structures like skin, tendon, ligaments, bones, dentin, or cornea. It is often associated with CIII and the ratio of the two types can change under physiological as well as under pathological conditions. ${ }^{11}$

The occurrence of CVI is associated with $\mathrm{CI}$ and $\mathrm{CIII}^{12}$ and even undulin, a noncollagenous ECM protein that is often found together with other collagens. ${ }^{13}$ The tenascin family consists of 5 glycoproteins and tenascin $\mathrm{X}$ is expressed from the myoblasts during the early stages of skeletal muscle development. In the further course, it can only be found at the muscle-tendon transition-zone. ${ }^{14}$ Tenascines can be reexpressed in adults in processes like wound healing and tissue involution or in pathologies like tumorigenesis and metastasis. $^{15}$

In humans, 23 different MMPs are known and all of them degrade components of the ECM. Their activities are increased under repair or remodeling conditions. Their function is inhibited by four different TIMPs and in interaction with these MMPs are involved in physiological and pathological remodeling processes. ${ }^{7,16}$

With respect to the histopathology of clubfoot, fibrosis of muscles, tendon sheaths, and ligaments in the posteromedial foot area were already described in the middle of the past century. Thus, Fried ${ }^{17}$ described a thickening of the tendon of the M. tibialis posterior and a hard, fibrous mass completely surrounding the medial side of the talus.

Skeletal muscle fibers in humans are defined by the particular myosin heavy chain isoforms they express and, therefore, can be divided into "slow-twitch" (type I) and "fast-twitch" (types IIa, IIb, and IIx) fibers. There is a significant individual variability in fiber distribution in humans and also in different muscles even from the same person. ${ }^{18}$ The proportions of type I and type II fibers are similar in M. vastus lateralis and M. gastrocnemius (on average $43 \%$ vs 38\%), whereas the proportion of type I fiber is dominant $(73 \%)$ in M. tibialis anterior. ${ }^{19,20} \mathrm{We}$, therefore, concluded comparability between $\mathrm{M}$. vastus lateralis and $\mathrm{M}$. gastrocnemius also in terms of ECM.

In order to better understand the pathogenesis of patients with primary clubfoot, we examined whether there are quantitative changes in the ECM (based on common interstitial collagens like CI and CIII, microfilamentous collagens like CVI, noncollagenous proteins like undulin, and enzymes like MMP-2 and TIMP-2 that are known to play a role in fibrogenesis and fibrolysis) of muscles involved in the foot deformity of patients with primary clubfoot.

\section{Patients and methods Muscle biopsies}

Muscle biopsies of 30 patients with congenital clubfoot, which were treated with Crawford-McKay method (Clinic of Orthopedics, Universitiy of Berlin, Campus Benjamin Franklin), were examined (23 male and 7 female patients). 
The study was approved by the ethics committee of the Free University of Berlin; after completely describing the study to the subjects, written informed consent was obtained from the children's parents. Among the 30 patients, 18 were affected on one side and 12 on both sides. Twenty-five biopsies were taken during the first operative foot correction and 5 in the context of relapses. The age of the patients ranged between 4 months and 5 years and 7 months. Biopsies were taken from M. gastrocnemius, M. tibialis anterior and from the vastus lateralis of the M. quadriceps femoris. Biopsies from the M. quadriceps femoris were taken to exclude other neuromuscular disorders.

Using a biopsy needle (TYPE Magnum R; Bard Medical R), 22-mm long biopsies were taken from the M. vastus lateralis and M. tibialis anterior. Open biopsies from the M. gastrocnemius were taken during surgery. Specimens were prepared in fluid tubes (RINGER; Fresenius Kabi, Bad Homburg, Germany) and cooled between $5^{\circ} \mathrm{C}$ and $10^{\circ} \mathrm{C}$. Samples that underwent cytoprotective treatment with TISSUE TEC (Miles, Elkhart, IN, USA) were frozen at $-70^{\circ} \mathrm{C}$ and were cut into $8 \mu \mathrm{m}$ thin sections using a Cryotom (REICHERT) at $-20^{\circ} \mathrm{C}$.

\section{Immunohistology}

Further immunohistochemical analysis was carried out using alkaline phosphatase-anti-alkaline phosphatase technique. ${ }^{21}$ Polyclonal antibodies were used for CI, CIII, CVI and undulin, ${ }^{22-24}$ whereas monoclonal antibodies were used for tenascin, MMP-2, TIMP-1, and TIMP-2 (Novocastra Laboratories, Newcastle, UK).

The intensity and areas of ECM of the prepared samples was quantitatively measured by a computer-assisted measuring device consisting of a microscope (Zeiss Axioskop, 40× magnification), a camera (SONY CCD Color Video Camera, Modell:DXC-930 P), and measuring program (Zeiss KS 400 3.0, Microsoft Excel, 7.0).

From each examined muscles, 12 different colored areas of stochastically selected sections (software assisted) were measured. Colored areas were treated as equivalent to fibrosis. Mean values of the three muscles were compared in square micrometer.

\section{Statistics}

Values are expressed as mean $\pm \mathrm{SD}$. Normality was calculated using Shapiro-Wilk test. Comparison between the fibrotic areas of the three muscles was performed with Wilcoxon tests for non-parametric data. Mann-Whitney $U$-test was used to compare Mm. gastrocnemii between different groups (male/ female, one-sided/both-sided, and primary surgery/correction surgery). Significance was accepted at $p<0.05$.

\section{Results}

We found higher values in M. gastrocnemius for CI, CIII, CVI, and undulin in comparison with $\mathrm{M}$. vastus lateralis. However, values for TIMP-2 were reduced. We found no significant differences in the components of ECM between M. tibialis anterior and the M. vastus lateralis (Table 1).

A positive result for tenascin could only be found in the area of muscle-tendon transition but not between epi-, peri-, and endomysium (Figure 1). Areas of muscle-tendon transition were excluded from evaluation. No positive results were found in the representation of antibodies against TIMP-1 and MMP-2.

Antibody reaction for CI, CIII, CVI, and undulin showed a strong effect in the peri- and endomysium marked in the M. gastrocnemius (Figure 2). A complete coloring of these areas was not possible for TIMP-2 (Figure 3), but there were structures (most likely within cells) within the perimysium showing a marked reaction. These structures could be observed mainly in the M. quadriceps.

There were no quantitative differences between male and female or between patients affected on one side or both sides. In patients who underwent relapse surgery, CI, CIII, CVI, and undulin in the gastrocnemius were significantly higher ( $p \leq 0.001)$, whereas TIMP-2 was significantly lower $(p=0.018)$ (Table 2$)$. In this regard, the medians $\left(\mu \mathrm{m}^{2}\right)$ of M. quadriceps femoris vs gastrocnemius were as follows: for CI 9,100 vs 14,000; for CIII 11,000 vs 15,200; for CVI 10,200 vs 14,200; for undulin 8,900 vs 13,400; and for TIMP-2 640 vs 390.

\section{Discussion}

The results obtained clearly indicate changes in the ECM of M. gastrocnemius compared with M. quadriceps femoris as a result of fibrosis in patients with primary clubfoot.

Table I Mean values and SD for fibrosis in square micrometer

\begin{tabular}{|c|c|c|c|c|c|c|c|c|c|c|}
\hline & Collagen I & & Collagen III & & Collagen VI & & Undulin & & TIMP-2 & \\
\hline M. vastus lateralis $(n=30)$ & $7,942 \pm 340$ & & $9,633 \pm 278$ & & $9,713 \pm 220$ & & $9,187 \pm 168$ & & $932 \pm 71$ & \\
\hline M. gastrocnemius $(n=29)$ & $10,133 \pm 479$ & $p=0.000$ & 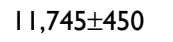 & $p=0.000$ & $11,396 \pm 385$ & $p=0.000$ & $10,349 \pm 29 \mid$ & $p=0.000$ & $711 \pm 62$ & $p=0.005$ \\
\hline M. tibialis anterior $(n=2 I)$ & $8,358 \pm 565$ & ns & $9,636 \pm 484$ & ns & $10,346 \pm 306$ & ns & $9,296 \pm 214$ & ns & $750 \pm 56$ & ns \\
\hline
\end{tabular}

Abbreviations: M., musculus; ns, not significant; TIMP-2, tissue inhibitor of matrixmetalloproteinase. 


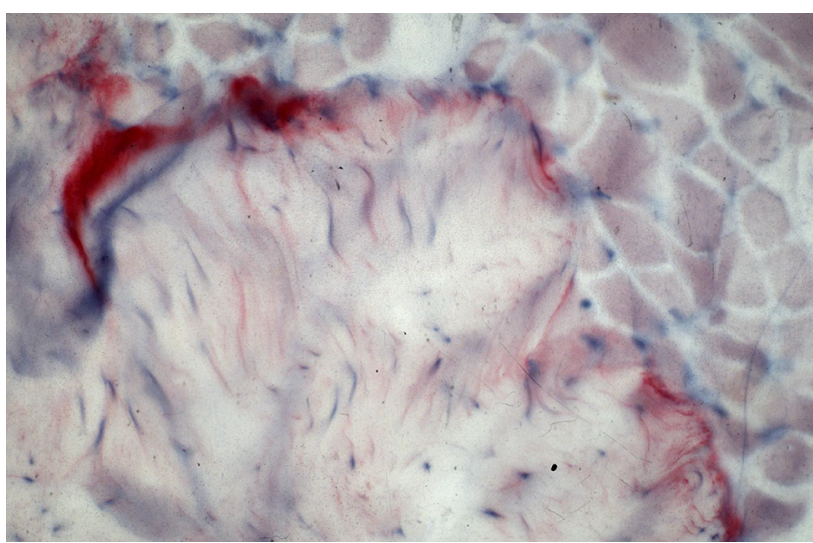

Figure I Antibody reaction (APAAP) for tenascin only in the area of the muscletendon transition zone.

Abbreviation: APAAP, alkaline phosphatase-anti-alkaline phosphatase.

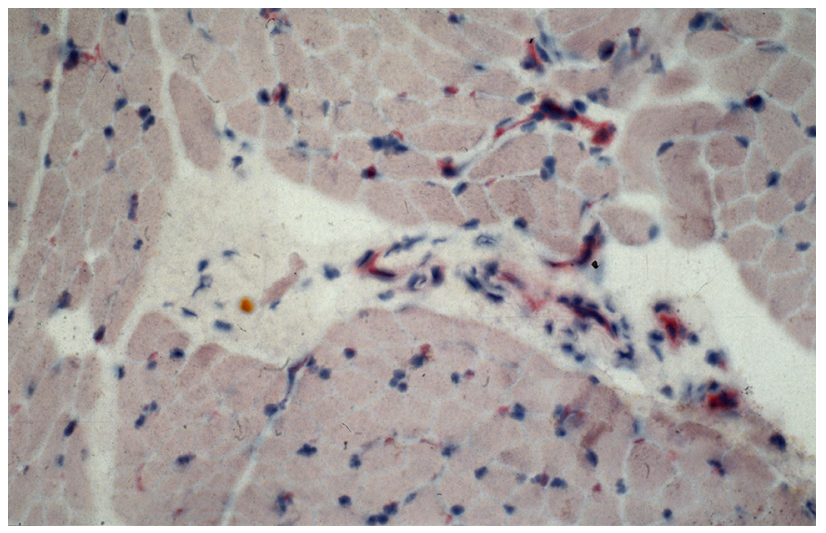

Figure 3 Antibody reaction (APAAP) for TIMP-2 pronounced in structures within the perimysium.

Abbreviations: APAAP, alkaline phosphatase-anti-alkaline phosphatase; TIMP-2, tissue inhibitor of matrix metalloproteinase-2.
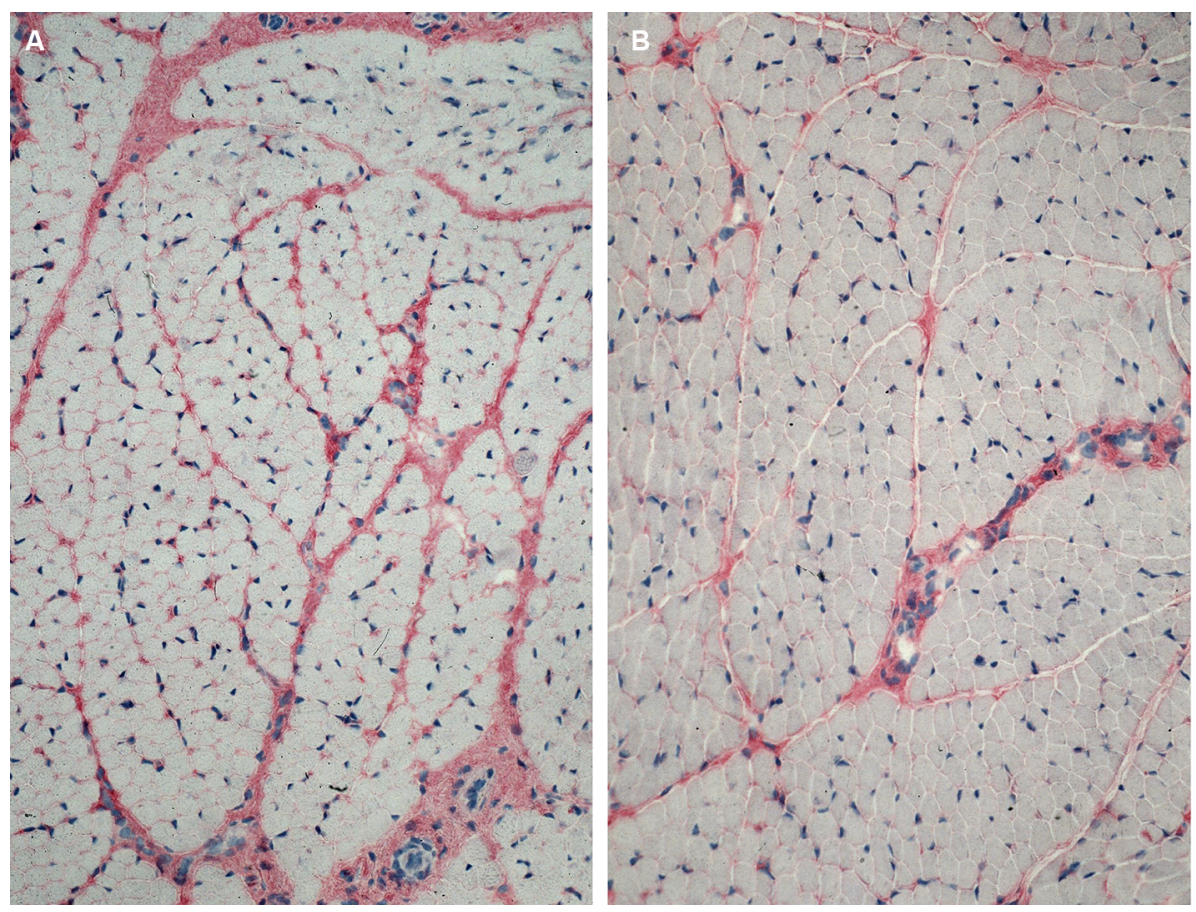

Figure 2 More intense antibody reaction (APAAP) for collagen I in the peri- and endomysium of M. gastrocnemius (A) in comparison with M. quadriceps femoris (B). Abbreviations: APAAP, alkaline phosphatase-anti-alkaline phosphatase; M., musculus.

Table 2 Comparison of the Mm. gastrocnemii of patients with first operative foot correction and re-OP through relapse

\begin{tabular}{llllll}
\hline Mann-Whitney U-test & Collagen I & Collagen III & Collagen VI & Undulin & TIMP-2 \\
\hline $\begin{array}{l}\text { First operative foot } \\
\text { correction }(n=24)\end{array}$ & 13 & 13 & 13 & 13 & 17 \\
$\begin{array}{l}\text { Re-OP through relapse } \\
(n=5)\end{array}$ & 27 & 26 & 26 & 27 & 7 \\
& $p=0.001$ & $p=0.001$ & $p=0.001$ & $p=0.001$ & $p=0.018$ \\
\hline
\end{tabular}

Abbreviations: Mm, musculi; TIMP-2, tissue inhibitor of matrixmetalloproteinase. 
Morphometric studies found a predominance of type I fiber in muscles involved in the formation of clubfoot (mainly Mm. gastrocnemii), leading to type II fiber deficiency ${ }^{25,26}$ responsible for small calves in these patients. This deficit could also be responsible for relapses in clubfoot because correction surgeries do not eliminate this imbalance. Loren et $\mathrm{al}^{27}$ described an increased incidence for a recurrence of clubfoot deformity after surgery in patients with an abnormal fiber distribution in M. peronaeus brevis. Likewise, increased fibrosis in the gastrocnemius could indicate a higher risk for relapse as observed in our 5 patients with a second correction surgery.

Contrary to these results regarding fiber distribution, a histochemical analysis of muscle biopsies in idiopathic clubfoot found normal fiber type ratios in 372 specimens (86.3\%) and muscle fiber atrophy in 55 specimens $(12.8 \%)$; only in 4 patients $(0.9 \%)$ type I fiber was predominant. These results in turn do not support the neuromuscular etiology of this disease. ${ }^{28}$

A MRI study showed a significant reduction in total leg volume and muscle volume and an increase in fat in the affected leg compared with the normal leg. During the treatment of resistant clubfoot, increased epimysial and intramuscular fats were present. ${ }^{29}$

Of the 50 specimens obtained from 6 patients with idiopathic clubfoot (among others taken from the medial and lateral capsules, and from the M. tibialis posterior and the Achilles tendon), Khan et al could not find myofibroblastlike cells or typical myofibroblasts and, therefore, excluded retracting fibrosis as a cause of contracture. ${ }^{30} \mathrm{In}$ contrast, in fetuses with clubfeet, there was a stronger CIII staining in the medial ligaments of the ankle joints and in the tibialis posterior insertion in comparison with normal fetal feet. The ligaments also showed completely disrupted collagen fibers and the soft tissues were contracted. Therefore, Fukuhara et al concluded that in severe clubfeet, fibromatosis is caused by myofibroblast-like cells before the third trimester of gestation; this leads to contraction and the typical clubfoot deformity. ${ }^{31}$

During muscle development, there is no significant change in fiber distribution from birth to adulthood, even though fiber size increases substantially. With increasing age, there is an extensive reduction in the number of satellite cells (essential for maintenance, repair, and hypertrophy of skeletal muscle) in muscle fiber areas in children. ${ }^{32}$ In muscular dystrophies accompanied by progressive fibrosis, there is an increasing occurrence of satellite cells that are responsible for the replacement of damaged muscle fibers. ${ }^{33}$ Referring to Nishimura et al, ${ }^{10}$ we would expect a decrease in ECM in the older patients. Nevertheless, the patients who underwent a second correction surgery had significantly higher markers of fibrosis, so we concluded that to be illness related.

TGF- $\beta$ and platelet-derived growth factor are involved in tissue injury healing and are expressed in higher levels in soft tissues of fibroproliferative disorders like Dupuytren's contracture. Contracted tissues in clubfeet share ultrastructural characteristics with Dupuytren's contracture. ${ }^{34}$ There is a prominent increase of endomysial and some perimysial connective tissues accompanied by an increased occurrence of $\mathrm{CI}$ and $\mathrm{CIII}$ in patients with dermatomyositis and Duchenne muscular dystrophy in comparison with healthy muscles ${ }^{35}$ similar to the $\mathrm{Mm}$. gastrocnemii of our patients with primary clubfoot. A blockade of growth factors leads to decreased collagen expression and fibroblast proliferation in cell cultures and, therefore, Klingberg et al concluded that a growth factor blockade may have the potential to improve the outcome in patients with clubfoot. ${ }^{36}$ Klingberg et al ${ }^{36}$ found a higher release of active TGF- $\beta 1$ from prestrained ECM in comparison with unorganized ECM, so mechanical prestraining determines pro-fibrotic activity of myofibroblasts and its impact on ECM remodeling/repair.

A proteomic analysis of the ECM in 13 patients with idiopathic pes equinovarus identified $19 \mathrm{ECM}$ proteins such as CI, CIII, CV, CVI, and CXII and TGF- $\beta$-induced protein ig-h3 in contracted tissues from the medial aspect of the talonavicular joint. For the first time, CV, CVI, and CXII were found in the ECM of patients with clubfoot. CVI can be degraded by trypsin (better than CI and CIII), so Ostadal et al concluded that a trypsin injection into the fibrotic areas might lead to a reduction of the contracture and, therefore, to a reduced number of surgeries. ${ }^{37,38}$ Our results confirm these data by finding increased reaction of collagenes in the mysies and support the hypothesis that primary clubfoot is of fibroproliferative origin.

In contrast to TIMP-1 and MMP-2, it was possible to identify TIMP-2 expressing cells within the mysies, where the mysies themselves were not stained. A study by Singh et $\mathrm{a}^{39}$ in human masseter muscle found intense TIMP-1 staining around each muscle fiber, in the interstices of the connective tissue, and surrounding blood vessels. MMP-2 mRNA and TIMP-2 mRNA could just be detected by RT-PCR and not with immunohistochemical techniques. We, therefore, concluded that TIMP-1 concentrations in our specimen were too low for immunohistochemical staining.

An imbalance between the synthesis and degradation of components of the ECM leads to fibrosis; MMPs and their 
precursors are activated in inflammatory and wound conditions; they degrade ECM components and are inhibited by TIMPs. ${ }^{16}$ TIMP-2 protects ECM from proteolysis and increases fibroblast proliferation as well as collagen production. ${ }^{16,40}$ It not only inhibits MMP-2 and other MMPs but is also involved in skeletal muscle maturation via MMP-2 activation. ${ }^{16}$ MMP-2 degrades ECM, but high levels of MMP-2 can also be found in increased fibrosis (as in Dupuytren's contracture), maybe to reduce excessive ECM deposition. ${ }^{40,41}$ High levels of TIMP-2 are associated with ECM accumulation.

However, TIMP-2 knockout mice showed motor dysfunction (pronounced during early postnatal development), increased nerve branching, and expression of acetylcholine receptors. ${ }^{42,43}$ In in vitro cultures, treatment with recombinant TIMP-2 rescues reduced TIMP-2(-/-) myotube size. ${ }^{43}$ In patients with systemic sclerosis, Yazawa et $\mathrm{al}^{44}$ found serum TIMP-2 levels to be significantly more elevated in a high disease activity group compared with low disease activity group, whereas serum MMP-2 did not differ compared to healthy controls. In induced liver fibrosis in rats, Iredale et $\mathrm{al}^{45}$ demonstrated a rapid decrease in the expression of collagenase inhibitors TIMP-1 and TIMP-2 during spontaneous resolution. In patients with Dupuytren's contracture, Ulrich et $\mathrm{al}^{41}$ described higher levels of TIMP-1, TIMP-2, and MMP-2 in comparison to normal fascia, which is in accordance with the results of Ratajczak-Wielgomas et $\mathrm{al}^{46}$ who found higher levels of MMP-2 and TIMP-2 mRNA in pathological-modified tissues with an imbalance between MMP-2 and TIMP-2.

We found a low level of TIMP-2 in the gastrocnemii, which is contradictory to the earlier results regarding fibrosis. We also concluded that immunohistochemical techniques are not the choice of technique to analyze MMPs and their inhibitors. We found a staining in structures within the mysies but not in the mysies itself. On the other hand, motor dysfunction observed in TIMP-2-knockout mice and reduced myofibrils are symptoms that are also seen in clubfoot patients. One possible explanation for low TIMP-2 values observed in the $\mathrm{M}$. gastrocnemius could be a simultaneous downregulation of TIMP-2 and the MMPs in the mysies, which would also cause an increase in ECM.

Besides the alterations of collagens, MMPs, and TIMPs, changes of dermatan-4-sulfotransferase 1 (D4ST1) and beta-catenin in patients with clubfoot are also described in the literature.

Loss of D4ST1 function was shown in patients with adducted thumb-clubfoot syndrome (ATCS), an autosomal- recessive disorder, which besides congenital contractures of thumbs and feet is characterized by typical facial appearance, thin and translucent skin, and deformities of heart, kidney, and intestine. This genetic defect leads to the failure of dermatan sulfate in patient's fibroblasts and accentuates its importance for the regular function of ECM. ${ }^{47}$ ATCS is the first human disorder that emphasizes the roles D4ST1 plays in human development and ECM maintenance. ${ }^{48}$

Beta-catenin mediates fibroproliferative response in fibroproliferative disorders like Dupuytren's disease. ${ }^{49}$ Poon et $\mathrm{al}^{50}$ studied the contracted tissues from 10 feet undergoing surgery for clubfeet using Western blotting analysis. The results indicate that CIII RNA expression is positively correlated with the protein level of beta-catenin, so beta-catenin plays an important role in regulating contracture in clubfeet.

\section{Conclusion}

Changes in the ECM of the M. gastrocnemius are of fibroproliferative origin. In contrast to other studies, we found increasing fibrosis not only in contracted tissues but also in the muscle itself. There are no changes in the ECM of the M. tibialis anterior, so its participation seems to be secondary. Increasing fibrosis in $\mathrm{M}$. gastrocnemius could be an indicator for a higher risk of relapse.

\section{Limitations}

We chose the vastuls lateralis of the $\mathrm{M}$. quadriceps femoris as healthy control muscle. Although fiber distribution is similar with M. gastrocnemius, a comparison between the affected and the unaffected side of the Mm. gastrocnemii would be even more meaningful. The number of patients who underwent a second correction surgery was very small, which restricts the general applicability of these results.

\section{Disclosure}

The authors report no conflicts of interest in this work.

\section{References}

1. Westhoff B, Krauspe R. Der Klumpfuß Ätiologie und Pathogenese [The Clubfoot: Etiology and Pathogenesis]. In: Döderlein L, Wenz W, Schneider U, editors. Der Klumpfuß. Berlin: Springer; 1999:3-6.

2. O'Shea RM, Sabatini CS. What is new in idiopathic clubfoot? Curr Rev Musculoskelet Med. 2016;9(4):470-477.

3. Dietz FR. On the pathogenesis of clubfoot. Lancet. 1985;1(8425): 388-390.

4. Dodwell E, Risoe P, Wright J. Factors associated with increased risk of clubfoot: a Norwegian national cohort analysis. J Pediatr Orthop. 2015;35(8):e104-e109.

5. Engell V, Nielsen J, Damborg F, et al. Heritability of clubfoot: a twin study. J Child Orthop. 2014;8(1):37-41. 
6. Sanes J. The extracellular matrix. In: Engel A, editor. Myology. vol. 1, 2nd ed. New York: McGraw-Hill; 1994:242-260.

7. Bonnans C, Chou J, Werb Z. Remodelling the extracellular matrix in development and disease. Nat Rev Mol Cell Biol. 2014;15(12):786-801.

8. Schuppan D, Somasundaram R, Dieterich W, Ehnis T, Bauer M. The extracellular matrix in cellular proliferation and differentiation. Ann NY Acad Sci. 1994;733:87-102.

9. Melo F, Carey DJ, Brandan E. Extracellular matrix is required for skeletal muscle differentiation but not myogenin expression. $J$ Cell Biochem. 1996;62(2):227-239.

10. Nishimura T, Ojima K, Hattori A, Takahashi K. Developmental expression of extracellular matrix components in intramuscular connective tissue of bovine semitendinosus muscle. Histochem Cell Biol. 1997;107(3):215-221.

11. Nimni ME. Collagen: structure, function, and metabolism in normal and fibrotic tissues. Sem Arthritis Rheum. 1983;13(1):1-86.

12. Keene DR, Engvall E, Glanville RW. Ultrastructure of type VI collagen in human skin and cartilage suggests an anchoring function for this filamentous network. J Cell Biol. 1988;107(5):1995-2006.

13. Zhang X, Schuppan D, Becker J, Reichart P, Gelderblom HR. Distribution of undulin, tenascin, and fibronectin in the human periodontal ligament and cementum: comparative immunoelectron microscopy with ultra-thin cryosections. J Histochem Cytochem. 1993;41(2): 245-251.

14. Burch GH, Bedolli MA, McDonough S, Rosenthal SM, Bristow J. Embryonic expression of tenascin-X suggests a role in limb, muscle, and heart development. Dev Dyn. 1995;203(4):491-504.

15. Jones FS, Jones PL. The tenascin family of ECM glycoproteins: structure, function, and regulation during embryonic development and tissue remodeling. Dev Dyn. 2000;218(2):235-259.

16. Alameddine HS, Morgan JE. Matrix metalloproteinases and tissue inhibitor of metalloproteinases in inflammation and fibrosis of skeletal muscles. J Neuromuscul Dis. 2016;3(4):455-473.

17. Fried A. Recurrent congenital clubfoot; the role of the M. tibialis posterior in etiology and treatment. J Bone Joint Surg Am. 1959;41-A(2):243-252.

18. Schiaffino $\mathrm{S}$, Reggiani C. Fiber types in mammalian skeletal muscles. Physiol Rev. 2011;91(4):1447-1531.

19. Johnson MA, Polgar J, Weightman D, Appleton D. Data on the distribution of fibre types in thirty-six human muscles. An autopsy study. J Neurol Sci. 1973;18(1):111-129.

20. Holmbäck AM, Porter MM, Downham D, Andersen JL, Lexell J. Structure and function of the ankle dorsiflexor muscles in young and moderately active men and women. J Appl Physiol (1985). 2003;95(6):2416-2424.

21. Cordell JL, Falini B, Erber WN, et al. Immunoenzymatic labeling of monoclonal antibodies using immune complexes of alkaline phosphatase and monoclonal anti-alkaline phosphatase (APAAP complexes) J Histochem Cytochem. 1984;32(2):219-229.

22. Schuppan D, Ruhlmann T, Hahn EG. Radioimmunoassay for human type VI collagen and its application to tissue and body fluids. Anal Biochem. 1985;149(1):238-247.

23. Schuppan D, Schmid M, Somasundaram R, et al. Collagens in the liver extracellular matrix bind hepatocyte growth factor. Gastroenterology. 1998;114(1):139-152.

24. Freise C, Erben U, Muche M, et al. The alpha 2 chain of collagen type VI sequesters latent proforms of matrix-metalloproteinases and modulates their activation and activity. Matrix Biol. 2009;28(8):480-489.

25. Mellerowicz H, Sparmann M, Eisenschenk A, Dorfmuller-Kuchlin S, Gosztonyi G. Morphometric study of muscles in congenital idiopathic clubfoot. In: Simons G, editor. The Clubfoot. Berlin: Springer; 1994:7-15

26. Kojima A, Nakahara H, Shimizu N, et al. Histochemical studies in congenital clubfeet. In: Simons G, editor. The Clubfoot. Berlin: Springer; 1994:16-21.

27. Loren GJ, Karpinski NC, Mubarak SJ. Clinical implications of clubfoot histopathology. J Pediatr Orthop. 1998;18(6):765-769.
28. Herceg MB, Weiner DS, Agamanolis DP, Hawk D. Histologic and histochemical analysis of muscle specimens in idiopathic talipes equinovarus. $J$ Pediatr Orthop. 2006;26(1):91-93.

29. Moon DK, Gurnett CA, Aferol H, Siegel MJ, Commean PK, Dobbs MB. Soft-tissue abnormalities associated with treatment-resistant and treatment-responsive clubfoot: findings of MRI analysis. $J$ Bone Joint Surg Am. 2014;96(15):1249-1256.

30. Khan AM, Ryan MG, Gruber MM, Haralabatos SP, Badalamente MA. Connective tissue structures in clubfoot: a morphologic study. J Pediatr Orthop. 2001;21(6):708-712.

31. Fukuhara K, Schollmeier G, Uhthoff HK. The pathogenesis of club foot. A histomorphometric and immunohistochemical study of fetuses. J Bone Joint Surg Br. 1994;76(3):450-457.

32. Verdijk LB, Snijders T, Drost M, Delhaas T, Kadi F, van Loon LJ. Satellite cells in human skeletal muscle; from birth to old age. Age (Dordr). 2014;36(2):545-547.

33. Smith LR, Barton ER. Regulation of fibrosis in muscular dystrophy. Matrix Biol. 2018;pii:S0945-053X(17)30411-0. doi: 10.1016/j. matbio.2018.01.014.

34. Li C, Nguyen Q, Cole WG, Alman BA. Potential treatment for clubfeet based on growth factor blockade. J Pediatr Orthop. 2001;21(3):372-377.

35. Foidart M, Foidart JM, Engel WK. Collagen localization in normal and fibrotic human skeletal muscle. Arch Neurol. 1981;38(3):152-157.

36. Klingberg F, Chow ML, Koehler A, et al. Prestress in the extracellular matrix sensitizes latent TGF-betal for activation. J Cell Biol. 2014;207(2):283-297.

37. Ostadal M, Eckhardt A, Herget J, et al. Proteomic analysis of the extracellular matrix in idiopathic pes equinovarus. Mol Cell Biochem. 2015;401(1-2):133-139.

38. Ostadal M, Liskova J, Hadraba D, Eckhardt A. Possible pathogenetic mechanisms and new therapeutic approaches of pes equinovarus. Physiol Res. 2017;66(3):403-410.

39. Singh A, Nelson-Moon ZL, Thomas GJ, Hunt NP, Lewis MP. Identification of matrix metalloproteinases and their tissue inhibitors type 1 and 2 in human masseter muscle. Arch Oral Biol. 2000;45(6):431-440.

40. Arpino V, Brock M, Gill SE. The role of TIMPs in regulation of extracellular matrix proteolysis. Matrix Biol. 2015;44-46:247-254.

41. Ulrich D, Ulrich F, Piatkowski A, Pallua N. Expression of matrix metalloproteinases and their inhibitors in cords and nodules of patients with Dupuytren's disease. Arch Orthop Trauma Surg. 2009;129(11):1453-1459.

42. Jaworski DM, Soloway P, Caterina J, Falls WA. Tissue inhibitor of metalloproteinase-2(TIMP-2)-deficient mice display motor deficits. J Neurobiol. 2006;66(1):82-94.

43. Lluri G, Langlois GD, Soloway PD, Jaworski DM. Tissue inhibitor of metalloproteinase-2 (TIMP-2) regulates myogenesis and beta1 integrin expression in vitro. Exp Cell Res. 2008;314(1):11-24.

44. Yazawa N, Kikuchi K, Ihn H, et al. Serum levels of tissue inhibitor of metalloproteinases 2 in patients with systemic sclerosis. $J$ Am Acad Dermatol. 2000;42(1 Pt 1):70-75.

45. Iredale JP, Benyon RC, Pickering J, et al. Mechanisms of spontaneous resolution of rat liver fibrosis. Hepatic stellate cell apoptosis and reduced hepatic expression of metalloproteinase inhibitors. J Clin Invest. 1998;102(3):538-549.

46. Ratajczak-Wielgomas K, Gosk J, Rabczynski J, et al. Expression of MMP-2, TIMP-2, TGF-beta1, and decorin in Dupuytren's contracture. Connect Tissue Res. 2012;53(6):469-477.

47. Dundar M, Muller T, Zhang Q, et al. Loss of dermatan-4-sulfotransferase 1 function results in adducted thumb-clubfoot syndrome. Am J Hum Genet. 2009;85(6):873-882.

48. Zhang L, Muller T, Baenziger JU, Janecke AR. Congenital disorders of glycosylation with emphasis on loss of dermatan-4-sulfotransferase. Prog Mol Biol Transl Sci. 2010;93:289-307.

49. Degreef I, De Smet L, Sciot R, Cassiman JJ, Tejpar S. Beta-catenin overexpression in Dupuytren's disease is unrelated to disease recurrence. Clin Orthop Relat Res. 2009;467(3):838-845.

50. Poon R, Li C, Alman BA Beta-catenin mediates soft tissue contracture in clubfoot. Clin Orthop Relat Res. 2009;467(5):1180-1185. 


\section{Publish your work in this journal}

Orthopedic Research and Reviews is an international, peer-reviewed, open access journal that focusing on the patho-physiology of the musculoskeletal system, trauma, surgery and other corrective interventions to restore mobility and function. Advances in new technologies, materials, techniques and pharmacological agents are particularly

welcome. The manuscript management system is completely online and includes a very quick and fair peer-review system, which is all easy to use. Visit http://www.dovepress.com/testimonials.php to read real quotes from published authors.

Submit your manuscript here: https://www.dovepress.com/orthopedic-research-and-reviews-journal 